\title{
sobre: El tiempo de la improvisación, de Alberto Giordano. Rosario: Iván Rosado, 2019 .
}

BRUNO GROSSI Universidad Nacional del Litoral - CONICET, Argentina / brunomilan@hotmail.com

\author{
Pascal había «encontrado», pero sin duda porque ya no buscaba más. El cese de la búsqueda, \\ y la forma de ese cese, puede dar la sensación de hallazgo. Pero nunca tuvo fe \\ en la búsqueda en tanto ésta aguarda en lo imprevisto \\ Valéry
}

El tiempo de la convalecencia (el primer tomo de los diarios autobiográficos que Giordano llevó en facebook) se leía con la misma felicidad con la que se lo escribió: la dicha de una sintaxis que instaura, mientras dura, un modo de existencia anómalo que da lugar tanto a la libre expresión de la sofisticación como de la estupidez. No otro es su hallazgo: el ejercicio del intimismo espectacular generaba las condiciones propicias para pasar del lúcido análisis crítico sobre sus lecturas al comentario de un episodio trivial de la vida cotidiana. La conjunción heterogénea, lejos de resentir el conjunto, no hacía sino afianzarlo, vivificarlo. El resultado era un libro que, como los de Puig que Giordano tanto ama, podía leer un becario y la madre de ese mismo becario. Sin embargo, el tono melancólico del final, el aura mortuoria por un lado y de summa, de «logro» alcanzado por el otro, no hacía sino enrarecerlo: la certeza, explicitada por el propio Giordano, que la felicidad, tal como había sido vivida y quedado fijada en la época de convalecencia, estaba oficialmente terminada. De allí que la última entrada del diario, lacónica y admonitoriamente sugería que otro tiempo comenzaba: el de la improvisación.

Si Giordano encontró en «Mucho tiempo he estado acostándome temprano» de Barthes la conjura contra el tedio de la especialización, hallando en él un modo inédito de vincular sus inclinaciones ensayísticas y literarias, una frase de ese mismo texto vuelve ahora, en el contexto del nuevo libro, como un dictum, una amenaza o un vaticinio: «Cuando haya acabado este texto, esta conferencia, ¿ya no tendré nada más que hacer sino empezar otro, otra?» 401). Barthes, jugando a ser el Lenin de la Teoría literaria, formulaba así una inquietante pregunta de alcances formales y existenciales. ¿Pero no supone tal interrogante, en cierta manera, todavía un telos, una dirección hacia donde el pensamiento debe dirigirse, un fundamento que daría sentido a cada texto

Para citar este artículo: Grossi, B. (2019). Sobre: El tiempo de la improvisación, de Alberto Giordano. El taco en la brea, 10 (junio-noviembre), 230-234. Santa Fe, Argentina: UNL. DOI: 10.14409/tb.v1i10.8704 
individual? Aun cuando la repetición que paraliza, la melancolía que hace dudar de las propias capacidades y la identidad como refugio frente a lo exterior reaparezcan cada tanto de El tiempo de la improvisación, hay en el diario la felicidad y la angustia de un pensamiento no sometido ya al respaldo de valores trascendentes (ni siquiera los de la convalecencia). El acto, el instante, la clase, el ensayo, el posteo de facebook no son por lo tanto el medio para otra cosa, no tienen ninguna meta ni sirven a ninguna causa. La vida es así liberada de todo fin exterior. «La ruptura con las entidades morales - dice Bataille — le brindan al aire respirado una verdad tan grande que se preferiría vivir como un invalido o morir antes que volver a caer en la servidumbre» (19). Sin embargo, por eso mismo la vida se vuelve de pronto más incierta, más frágil. La pregunta de Barthes, reformulada entonces por Bataille, podría plantearse más o menos así: ¿Qué hacer, si somos nietzscheanos consecuentes, cuando ya no queda nada por hacer, cuando ya nada es necesario? Una posible respuesta sería: improvisar, jugar, entregarse al azar, es decir, guiar la propia acción por un principio de libertad absoluto, aunque eso implique quizás el extravío y la intimidad con el abismo. A propósito dice Giordano: «Al sinsentido le debemos todo, lo que nos arrastra y nos eleva, lo que nos consume y nos expande. Es lo que reúne, si las condiciones fueron favorables, y también lo que separa» (281). La voluntad de suerte a la que nos encomendamos es lo que nos permite en definitiva explorar y ampliar los márgenes de lo posible.

Ahora bien, ¿cómo podemos pensar esta afirmación insensata dentro de los márgenes modestos de la crítica literaria? Primero: liberándola de toda moral del resultado, el interés y la utilidad que reina en el mundo del saber institucionalizado; segundo: hacer de cuenta que el saber, o mejor, la experiencia de búsqueda del saber, podría transformar nuestras vidas, volverlas más interesantes; y tercero: poner en juego dicho saber, porque solo aquello que se arriesga, se gasta soberanamente intensifica la experiencia.

Lo bueno de este tipo de proyectos es que son innecesarios e inútiles, como los juegos, así que, salgan como salgan, no pueden fallar. En nuestro campo, el del fracaso es solo un fantasma que solo acosa a los burócratas. (113-114)

El ensayista es, por definición, alguien que aprende a no administrarse, advertido como está de que el error y el malentendido son condiciones y herramientas de su ejercicio. (39)

El riesgo mayor al que se expondrían quienes consiguen suspender la sanción de los adjetivos, los que experimentan la afirmación en bruto del placer y el vértigo de trazar, es el enrarecimiento o la casi extenuación de la identidad profesional (...) Esta máxima invita a desprender el acto de su valor institucional y a tolerar el carácter provisorio y evanescente de cualquier resultado. (...) ¿Se puede enseñar a contar con la fragilidad como recurso y no solo como obstáculo? ¿Se puede enseñar a no administrarse, incluso a perder desinteresadamente? Cuanto más radical se vuelve la duda, más se fortalecería la convicción de que vale la pena insistir. Hay vitalidad, incluso alegría, en esos estados de crisis. (42)

Hay en Giordano un desprecio anarco-aristocrático hacia el trabajo que emociona. Durante las 289 páginas no asistimos sino a sus múltiples intentos de evadirse de la responsabilidad, las obligaciones y el deber. De hecho llega a decir, guiado por el espíritu de Cioran, que su máxima aspiración es llegar a convertirse en un maestro del ocio, un verdadero maestro en el arte de perder el 
tiempo. Sin embargo, uno podría sospechar la impostura de tal estado de acedia o ataraxia, ya que Giordano efectivamente no hace otra cosa que trabajar, es decir, leer, pensar, escribir, dar clase. De allí que resulta evidente que es el concepto mismo de trabajo, la idea de seriedad, esfuerzo, sacrificio, resultado, coerción con la que está asociado, lo que parece en definitiva recusado. ¿No es, por otra parte, lo que se dejaba leer ya en Un filósofo de Aira, novela que tranquilamente podría haberse llamado Un crítico literario, o mejor Un investigador-ensayista, o sencillamente Alberto Giordano?

Era paradójico: cuando estaba en su despacho, ejerciendo el trabajo por el que le pagaban, que básicamente consistía en pensar, no sentía que estuviera pensando sino más bien que apilaba pesadas rocas de palabras con las que intentaba sin éxito levantar una pirámide de conceptos, que terminaría siendo una tumba porque sentía que el esfuerzo lo estaba matando. Y cuando no trabajaba, cuando nada lo obligaba a pensar, ahí se desplegaba su pensamiento, y lo hacía con el contento con el que un niño se sube a una calesita. (14)

No habría que leer la novela de Aira (o el diario de Giordano) como una crítica abstracta del trabajo disciplinar, ni tampoco como una afirmación gozosa del pensamiento privado, sino como la escisión dolorosa que ocurre al interior del sujeto cuando fuerzas exteriores limitan los deseos transmutándolos en obligaciones. De allí el escepticismo radical de Giordano a aquello en lo que las instituciones académicas se convirtieron. No es casual que aparezca, en este contexto, el grupo de estudio elevado casi a la categoría de espacio utópico: ajenos a las lógicas de poder y al utilitarismo del certificado, en ellos late todavía la alegría de ejercitarse, de experimentar las potencias voluptuosas de la lectura (por eso también, por otra parte, el elogio del autodidacta, como aquel que - al margen de cierto resentimiento en torno de las virtudes de las que se presume excluido- mantiene una relación desinteresada con el saber). En este punto resulta significativa su búsqueda de nuevas formas de sociabilidad que resulten convenientes para jugar e intensificar lo ambiguo e indeterminado de los conceptos. Casi como si Giordano invirtiera el razonamiento: la sociabilidad está al servicio del pensamiento y no el pensamiento de la sociabilidad. La imagen misma del paraíso se encarna por lo tanto en la conversación ociosa sobre lecturas circunstanciales. Es lo que leemos recurrentemente en el diario: las charlas de amigos (uno por vez: hasta en eso Giordano es barthesiano), aun cuando versen sobre tópicos banales son siempre proto-ensayismo salvaje, porque en ellas el pensamiento, aun en su desprolijidad, o por eso mismo, rozan algo así como una verdad. Dice Adorno:

Si se accediera por una vez a seguir el dudoso precepto de que la exposición debe reproducir el proceso del pensamiento, este proceso sería tan poco el de un proceso discursivo peldaño a peldaño como, a la inversa, un venirle al conocedor del cielo sus ideas. El conocimiento se da antes bien en un entramado de prejuicios, intuiciones, inervaciones, autocorrecciones, anticipaciones y exageraciones; en suma, en la experiencia intensa y fundada, mas en modo alguno transparente en todas sus direcciones. (86)

Es verdad que ni la oralidad ni la improvisación caótica son el modelo de la escritura de Giordano (por el contrario: hay en él una insistencia por el rigor y la precisión conceptual), pero en su alejamiento momentáneo del paper da la impresión de latir menos su rechazo al modelo convencional de escritura científica (que mal que pueda puede ser burlado disfrazando los ensayos 
en artículos) que el deseo radical, peligroso, destructivo de sustraerse de aquello mismo que es necesario para escribir un paper: la argumentación.

\begin{abstract}
A salvo de los disciplinamientos de la vida académica, la curiosidad de Marcelo como lector se me antoja una especie de paraíso que perdí cuando me convertí en crítico. Por suerte quedan las series, la música y las películas. Jamás escribiría sobre ellas. (122)
\end{abstract}

Si de verdad fuese a escribir un ensayo, seguiría la pista de Pavese en Saccomano lo más lejos que la imaginación me permitiese llegar, hasta aproximarme al deslumbramiento por la literatura italiana que viví en mis tiempos de estudiante. También seguiría la pista de Vittorini, el de Conversaciones en Sicilia, librando la argumentación al deseo de reanimar las promesas de aquel tiempo perdido. (88)

Facebook ha sido la ocasión de realizar auténticos ejercicios ensayísticos, de «conjurar el tedio de la especialización» saltando de un tema a otro, mezclando registros, apuntando esbozos de lectura sin la obligación de tener que desarrollarlas argumentativamente. (139)

\begin{abstract}
Al detestable género de la exposición académica, que apunta a justificar de manera verosímil las conclusiones de las que partió, Desanti opone la imagen del pensamiento como un viaje, que «se anuncia sobre un fondo de errancia que hay que asumir y atravesar para encontrar el propio camino, que no está trazado de antemano». Cuanto más propio sea ese camino, más sujeto estará a la ocurrencia de desvíos imprevistos y callejones sin salida. Como la vida, el pensamiento es un juego pautado por la alternancia entre interrupción, pérdida y recomienzo. (256)
\end{abstract}

El orden de las citas (que respeta los del libro solo parcialmente) sugiere una progresión: de la renuencia inicial de escribir sobre ciertos objetos por miedo a «contaminarlos» con los instrumentos de la especificidad a finalmente el ensayo que se escribe azarosa y felizmente olvidando las premisas a partir de las cuales partió, pasando por la afirmación de un ensayo que se escribe prescindiendo de la argumentación a otro que directamente solo se la postula borgeanamente. Lo que se deja intuir en estos fragmentos es menos el deseo de celebrar el goce sensible pre-conceptual (aunque este debería ser redimido de la violencia a la que lo somete la crítica académica) que de afirmar lo que la argumentación le hace al pensamiento. Es como si en todo ensayo - tal como lo piensa Giordano - hubiera al comienzo una hipótesis feliz y el ensayista querría a quedarse vivir con esa sola hipótesis, es decir desplegarla, mostrar sus contradicciones internas, analizar cómo se originó, etc.; pero sólo con ella. El problema es que un ensayo o un artículo (ni digamos una tesis, un libro) requiere la invención de hipótesis suplementarias que indefectiblemente traicionan la hipótesis original; no porque la contradigan, sino porque operan como concesiones retóricas, de las cuales el ensayista no cree, o de las cuales se autoconvence y que le permiten avanzar a precio de diluir la potencia originaria del pensamiento. Por eso a la lógica de la argumentación se la reemplaza con la de la improvisación, es decir, con un proceder que sabe lo que ignora y aun así se adentra en ello gozosamente.

«Nunca se llega tan lejos como cuando no se sabe hacia dónde se va» (78) dice Giordano epigramáticamente, luego de comentar que va a realizar un viaje a su pueblo natal a las 12:45 y que se levantó a las 8:45, lo que le da el tiempo suficiente para realizar sus actividades normalmente, 
pero que el recuerdo de la inminencia del viaje, el leve trastrocamiento del hábito lo lleva a un estado de embotamiento, de suspensión del tiempo, a un momento de total estupidez digno de Larry David o Louis CK. El abismo entre la máxima moral y el patetismo de la escena de la cual se desprende genera un efecto risible que, lejos de anular la verdad de la sentencia, acentúa lo que Giordano no hizo sino desarrollar durante todo el tiempo: que la seriedad, la falta de disposición para jugar con lo ambiguo, inmoviliza, aquello que la gracia, la ocurrencia, la improvisación libera.

\section{Referencias bibliográficas}

Adorno, T.W. (1951). Minima Moralia. Madrid: Akal, 2004.

Aira, C. (2018). Un filósofo. Rosario: Ivan Rosado.

Barthes, R. (1982). Mucho tiempo he estado acostandome temprano. En El susurro del lenguaje. Buenos Aires: Paidós, 2003.

Bataille, G. (1945). Sobre Nietzsche. Buenos Aires: Cuenco del plata, 2017. 